Kansas State University Libraries

New Prairie Press

\title{
THE ONSET, CESSATION, AND RATE OF GROWTH OF LOBLOLLY PINES IN THE FACE EXPERIMENT
}

Susanne Aref

David J. Moore

Evan H. DeLucia

Follow this and additional works at: https://newprairiepress.org/agstatconference

Part of the Agriculture Commons, and the Applied Statistics Commons

\section{(c) (1) $\Theta(9$}

This work is licensed under a Creative Commons Attribution-Noncommercial-No Derivative Works 4.0 License.

\section{Recommended Citation}

Aref, Susanne; Moore, David J.; and DeLucia, Evan H. (2004). "THE ONSET, CESSATION, AND RATE OF GROWTH OF LOBLOLLY PINES IN THE FACE EXPERIMENT," Conference on Applied Statistics in Agriculture. https://doi.org/10.4148/2475-7772.1154

This is brought to you for free and open access by the Conferences at New Prairie Press. It has been accepted for inclusion in Conference on Applied Statistics in Agriculture by an authorized administrator of New Prairie Press. For more information, please contact cads@k-state.edu. 


\title{
THE ONSET, CESSATION, AND RATE OF GROWTH OF LOBLOLLY PINES IN THE FACE EXPERIMENT.
}

\author{
Susanne Aref, Virginia Tech, David J. Moore and Evan H. DeLucia, UIUC
}

The Duke Forest FACE experiment was set up to investigate the impact of elevated $\mathrm{CO}_{2}$ levels on a larger eco system. One of the studies dealt with the impact of elevated $\mathrm{CO}_{2}$ levels on the onset and cessation of growth of loblolly pine trees (Pinus taeda L.). In this study the times of these events were determined for each year, 1996 - 2002. The rate of growth, the growth duration, and actual growth were determined from the models of onset and cessation of growth. Adjusted for initial basal area, the rate of growth, the actual growth, and the current basal area were slightly greater for elevated $\mathrm{CO}_{2}$ levels. There was no difference between the two $\mathrm{CO}_{2}$ levels for any of the time variables, onset, cessation, and growth period.

\section{INTRODUCTION}

In the past 100 years the level of Carbon Dioxide has risen dramatically and may well continue to do so. The Forest-Atmosphere Carbon Transfer and Storage (FACTS-I) is an experiment created to study the effects of elevated carbon dioxide levels on larger ecosystems. The FACTS-I experiment uses Free Air Carbon Dioxide Enrichment (FACE) technology to maintain elevated levels of atmospheric $\mathrm{CO}_{2}$ in a large area. A FACE experiment was started in 1996 in a plantation in the Duke Forest of 15 year old loblolly pine (pinus taeda). One part of the experimental set-up involves six large (30m diameter) rings with pipes that blow air into the rings (Figure 1, face.env.duke.edu/description.cfm). The six rings were organized as three pairs, where one ring in each pair received ambient air, while the other received elevated levels of $\mathrm{CO}_{2}$. The elevated level of $\mathrm{CO}_{2}$ was held at $200 \mu \mathrm{l} / \mathrm{l}$ above the ambient level of about $360 \mu \mathrm{l} / \mathrm{l}$.

One of the many teams of scientists working with Duke Forest FACE Experiment studied the onset and cessation of growth of loblolly pines from 1996 through 2002 (Moore et al., 2004). Further data may not be available or be relevant for the data already obtained since there was a severe drought in 2002 and in 2003 an ice storm downed a number of trees which led to changes in the canopy cover. About 30-40 trees in each ring (totaling 209 trees) were selected along walkways in each ring (Figure 2).

\section{MATERIALS AND METHODS}

The trees were sized into four categories based on diameter at breast height (dbh) quantiles of all loblolly pines in the six rings. The selected trees were outfitted with springloaded stainless steel dendrometer bands and diameter changes were recorded every month (Figure 3). The basal area was then calculated from the initial dbh and later diameter changes. The question of interest for this study was whether elevated $\mathrm{CO}_{2}$ levels changed the onset and/or cessation of growth, and thereby possibly the growth period. Since there were only six observations in a block design with three blocks, the level of significance for the treatment differences between ambient and elevated $\mathrm{CO}_{2}$ levels was set to be $10 \%$, rather than the usual $5 \%$. The elevated $\mathrm{CO}_{2}$ level was conjectured to result in faster growth, so that the growth, rate of 
growth, actual basal area should be larger at the elevated $\mathrm{CO}_{2}$ level. The larger growth would be consistent with an earlier onset, a later cessation, and a longer growth period. The alternative hypotheses for the $\mathrm{CO}_{2}$ treatment should therefore be one-sided and p-values from tests of $\mathrm{CO}_{2}$ treatments were therefore compared to $20 \%$ (if the difference was in the right direction).

The basal area for an individual tree appeared to be fairly constant through winter and then rapidly increased in spring. Often there was a decrease in basal area just before the onset of growth in spring. If the year had a dry period during growing season, there was a decrease in growth for those months though the growing season was not over, see Figure 4. The particular changes in increased or decreased growth were evident across most trees. In a few cases it was difficult to decide if an observation was an outlier since the other trees had the same pattern though not as extreme.

Parametric models consisting of straight lines and quadratic polynomials were used to determine the onset and cessation. For each year the onset of growth was determined from a model of the basal area on a time interval starting late in the previous year and ending late in the current year. The model was a segmented model that consisted of a horizontal line with a time break point, the onset of growth, where growth increased as a quadratic curve.

Most trees were fitted in a general way for each year, while some needed an adjustment in the fitting process without sacrificing the general approach. The onset of growth could not be fitted in 2001 for 37 trees. This was due to a constant basal area for three months in a row in the peak of the growth period for that year (Figure 5). The reason for the constant basal area was a drought during that period. For these trees only the basal area for the middle month of the three months in question was used together with the remaining months. The 2002 season had fairly nonstandard weather during the growing season, so that it was hard to tell whether there was an early time of onset and then some delay or a much later onset than in other years. For the onset of growth variable the 2002 data were not used, while for the starting basal area and rate variables the 2002 data were used.

\section{MODELS}

The model for time of onset of growth was:

Basal area $= \begin{cases}\text { start, } & \text { if date }<\text { onset } \\ \text { start }+ \text { rate }(\text { date-onset })+\text { curvature }^{*}(\text { date-onset })^{2}, & \text { if date } \geq \text { onset }\end{cases}$

For each year the date in the model was set to begin at 0 which was Oct 25 in the previous year. The data was fitted from that date through Oct 9 in the year in question. Exceptions to this time frame were as follows: In 199912 trees were fitted on an interval that went from Oct 25, 1998 through Oct 29, 1999; in 2001 the interval went from Nov 24, 2000 through Nov 28, 2001; in 1997 through 2001 the starting value for onset of growth was set to be between 140 and 160 days corresponding to last half of March, while in 2002 it was set to 210 corresponding to third week of May. The initial value for the parameter start was set to 200 in 1996 increasing to 310 in 2002, while the initial value for the parameter rate was set to 0.25 and the initial value for the parameter curvature was set to -0.0003 . 
Using SAS proc nlin a typical model statement was:

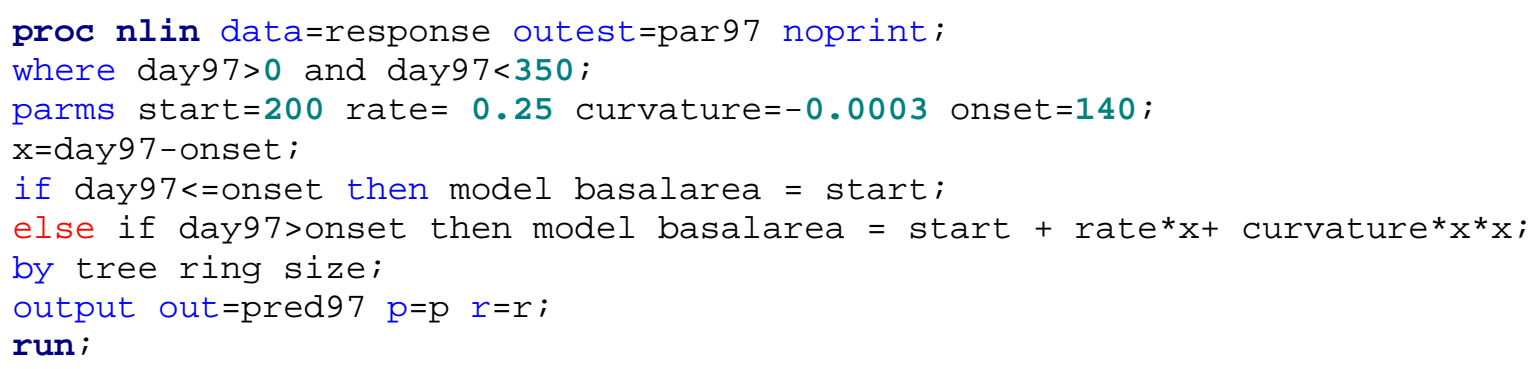

Similarly the time of cessation of growth was modeled from about the time of onset of growth one year into the next year - again as a segmented model, with a quadratic curve ending in a plateau with a differentiable knot between the quadratic and the plateau parts (Figure 6). The cessation time is the differentiable knot. The last part of the growth tapers off rather slowly so the actual cessation is therefore not as precise as the onset. The decision was made to determine the date where a large percentage $(90 \%, 95 \%$ or $99 \%)$ of the growth had occurred. The cessations at each of these percentage growth points varied more as the percentage increased. The time at which $95 \%$ of the growth had taken place was used in the analysis.

The model for cessation of growth was:

Basal area $= \begin{cases}\text { start }+ \text { rate*date }+ \text { curvature*date }{ }^{2}, & \text { if date }<\text { cessation } \\ \text { start }+ \text { rate }^{*} \text { cessation }+ \text { curvature* }^{*} \text { cessation }^{2}, & \text { if date } \geq \text { cessation }\end{cases}$

The initial value for the parameter start was set to 150 in 1996 increasing to 290 in 2002, while the initial value for the parameter rate was set to 0.25 and the initial value for the parameter cessation was set to 340. The parameter curvature was obtained from the cessation parameter from the equation

$$
\text { curvature }=\text { - rate/(2cessation). }
$$

Using SAS proc nlin a typical model statement was:

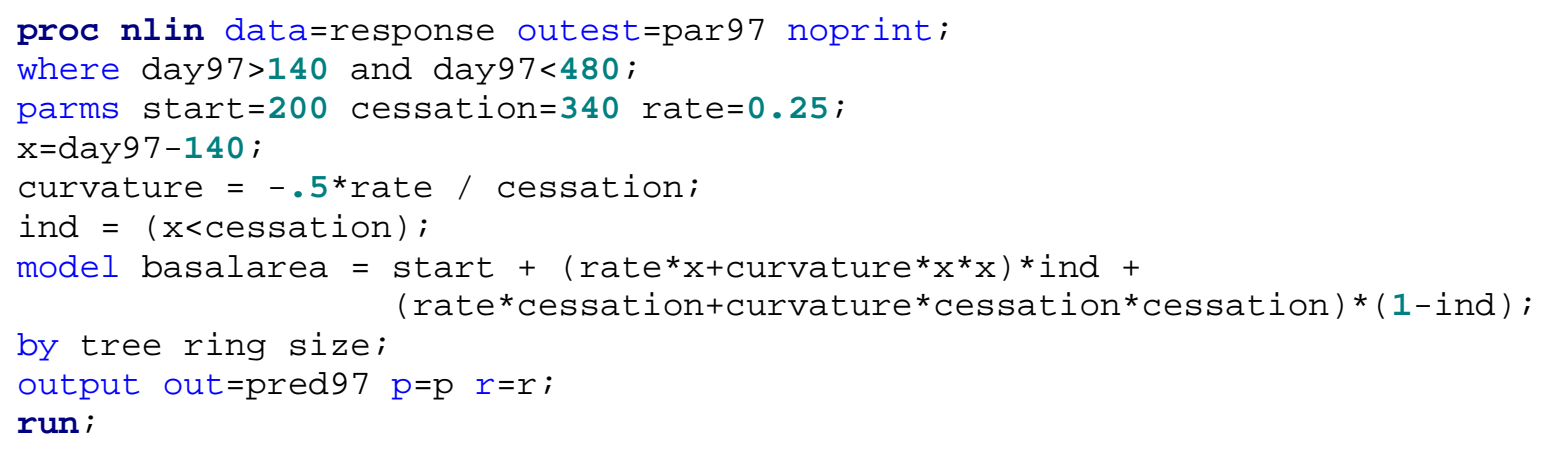

The starting basal area of one year should be the final basal area size of the previous year, indeed the correlation between the two variables was 0.99999 . The regression of one variable on 
the other variables had an estimated intercept of 0.054 that was not significant at $15 \%$ and a slope of 0.9999 in a model with an $\mathrm{R}^{2}$ of 1 . The differences between the two measurements range from -1.55 to 3.83 with a median of -0.078 as compared to the basal areas for 1996 that ranged from 50 to 450 with a median of 200 approximately.

All the analyses of the different dependent variables had the same general structure: The full model fixed and random effects were the same, though the fixed effects left in the models and the structure of the repeated effect year were not the same for the different variables. The full linear model was as follows:

$$
\begin{aligned}
y_{i j k l m}= & \mu+P_{i}+T_{j}+(P T)_{i j}+S_{k}+(T S)_{j k}+(P T S)_{i j k}+\beta b_{i j k l} \\
& +\operatorname{tree}(P T S)_{(i j k) l}+Y_{m}+(T Y)_{j m}+(S Y)_{k m}+(T S Y)_{j k m}+\varepsilon_{i j k l m}
\end{aligned}
$$

where $\mathrm{P}$ was the pair; $\mathrm{i}=1$ to 3 , $\mathrm{T}$ was the treatment; $\mathrm{j}=1$ and $2, \mathrm{~S}$ was the size class, $\mathrm{k}=1$ to 4 ; $\mathrm{b}$ was the basal area for year 1996 (initial basal area); tree was the individual tree, $\mathrm{l}=1$ to about 200; Y was year, $m=1997$ to 2002; $\varepsilon$ was the error. The error had an autoregressive structure for starting basal area, yearly growth gain and growth period and had a compound symmetry structure for onset, cessation, and rate. The initial basal area for year 1996 was calculated as a weighted sum of the basal areas for the measurements on hand, which were from April through December. The April basal area received four times the weight of the other months. This variable was included as a covariate in the analyses, since in general larger young trees have faster growing rates than smaller young trees (Figure 7). The covariate was not as significant or not significant at all for the onset, cessation, and growth period variables (Figure 8). The squareroot transformation of the basal area and rate variables were used to obtain homogeneity of variance. The analyses were done with SAS proc mixed, SAS Institute version 8.1.

\section{RESULTS}

Onset

The analysis of the onset of growth showed that the treatment effect and interactions with treatment were not significant, while the year, size by year effects, and the initial basal area covariate were significant, Table 1 and Figure 9. The slope for the starting basal area covariate was negative for the covariate indicating that onset of growth happened slightly earlier for larger basal areas. The years were (not surprisingly) very different, with differences in sizes changing from year to year. Size was not significant by itself. Size classes do not have consistently different onsets after adjusting for initial basal area, while onsets differ from one year to the next.

\section{Cessation}

The initial basal area covariate did not add to the model for the cessation variable and was therefore dropped from the model. Treatments were not significant different for this variable either, while cessation varied with year. Since there was a significant treatment by year interaction the difference in cessation of growth of trees in the elevated and ambient treatments 
varied with year. Only in years 1996 and 2001 were there significantly later cessations for the elevated treatment than the ambient treatment. For other years the elevated treatment did not have significantly later cessations than the ambient treatment, indeed for some years the ambient treatment had later cessation estimates than the elevated treatment. Size class was not significant indicating that there were no overall differences between size classes, Table 2 . The size class by year interaction was significant, but like the treatment by year interaction differences were not showing any patterns.

\section{Growth period}

The growth period was more correlated with the cessation than with the onset, while onset and cessation was the least correlated, see Table 3. The analysis for the growth period variable was similar to the one for cessation, except initial basal area was significant with a positive slope, indicating that trees with larger initial basal area tended to grow for a longer period, Table 4. This agreed with the negative slope for the onset variable, larger trees start growing earlier and therefore for a longer period. Though the interaction of treatment and year was significant, none of the yearly differences between treatments were significant. In 1997, 1999, and 2001 the growth period for trees in the elevated treatment was longer than for trees in the ambient treatment, while in 1998 and 2001 it was the opposite.

Even though some significant differences between levels of $\mathrm{CO}_{2}$ exist for some years, it appeared that the differences between levels of $\mathrm{CO}_{2}$ did not add up to an overall treatment difference for any of the onset, cessation, or growth period variables.

Yearly basal area gain

The $\mathrm{CO}_{2}$ treatment was significant at $18 \%$, while the interaction with year was significant at 2\%, see Table 5 and Figure 10. The actual F-value was greater for treatment than the interaction; the two very different levels of significance were driven by the denominator degrees of freedom of 2 and 683, respectively. As seen in Figure 10 the difference between treatment levels was fairly consistent across years.

There was no consistent pattern in the levels of the size classes for each year, while the growth was always larger for the elevated $\mathrm{CO}_{2}$ level than the ambient level for each year. If it was a randomization trial the fact that the elevated level was greater than the ambient level in all 6 years would occur with a probability of $2^{-6}$ or $1 / 64=0.016$. Considering the total growth for the whole period, 1997-2002, the elevated and ambient $\mathrm{CO}_{2}$ levels differ at $6.5 \%$, while there was neither size effect nor interaction with size, see Table 6.

\section{Rate of growth}

The analysis of this variable was much like the analysis for the yearly basal area gain, see Table 7 and Figure 11. Treatment was significant at 19\% and the interaction with year was significant at 3\% with practically the same F-values. The least squares mean for rates in the elevated treatment was significantly greater than the least squares mean for rates in the ambient treatment at $20 \%$ every year except 2002, see Table 8 . Like the yearly treatment means for the 
basal area gain variable the yearly treatment means for rates also had a fairly parallel pattern for the two treatments over the years, see Figure 11.

\section{Current basal area}

Analysis results show that there was no loss of information by treating year as a continuous variable rather than a class variable for the yearly basal area variable, Table 9 and Figure 12. In the analysis with year as a class variable the least squares mean for elevated treatment level was significantly higher than the mean for the ambient treatment level at $15 \%$. From the model with year as a class differences occurred at size levels 2 and 3 from 1999-2002 and from 200-2002 for size level 4, while there were no differences for size level 1. The differences increased with time.

When year was modeled as a continuous variable with 0 being 1996, the treatment intercepts were statistically the same, meaning the covariate was working, while the size intercepts were significantly different. The least squares mean for the elevated treatment was significantly higher than the mean for the ambient treatment level at $17 \%$.

The slopes for year differed for the two levels of $\mathrm{CO}_{2}$ at 0.0001 . The slope for the elevated treatment was significantly greater than the slope for the ambient treatment for each year.

The slopes were also significantly different at 0.0001 for the size classes. Due to the relationship between the covariate and the size class, the estimated start levels were in the opposite order in 1997 size-wise (size 1 has the largest value followed by size 2, then size 3, and finally size 4). There was a change-over in 1999 and 2000, and in 2001 and 2002 the switchover is complete.

The growth variables were fairly correlated too, especially the growth gain and the rate of growth with a correlation coefficient at 92\%, see Table 10.

Correlations between growth and time variables

All correlations were significant at 5\%, Table 11. Yearly basal area and rate of growth were correlated with onset, cessation, and growth period in a very similar way. The yearly growth gain had the same pattern of correlation, a negative correlation with onset, and positive correlations with cessation and growth period, but the correlation coefficients were 2.5-3 times larger. The absolute values of the correlation coefficients for the cessation were 1.25-1.5 greater than the corresponding ones for the onset. The correlation coefficients for the growth period were slightly higher than the corresponding ones for the cessation.

\section{SUMMARY}

For loblolly pines there were evidence that highly elevated $\mathrm{CO}_{2}$ levels increased the rate and gain of growth. The onset and cessation of growth and therefore the growth period did not appear to be affected of elevated $\mathrm{CO}_{2}$ levels. The larger growth therefore appeared to depend on the accelerated rate only and not on an extended growth period. Also the higher rates of growth 
were not present for the lowest size class and not as pronounced for the largest size class as for the two middle size classes.

\section{REFERENCES}

Moore, David, J., Susanne Aref, Adrien Finzi, Jason Hamilton, Ringo M. Ho, Jeffrey S. Pippen, Evan, $\mathrm{H}$ DeLucia. Inter-annual variation in the response of tree growth and productivity of a Pinus taeda forest exposed to elevated $\mathrm{CO}_{2}$. Submitted to Global Change Biology, April 2004.

SAS Online Doc version 8. 1999. SAS/STAT User’s Guide, Cary, NC:SAS Institute Inc.

face.env.duke.edu/description.cfm

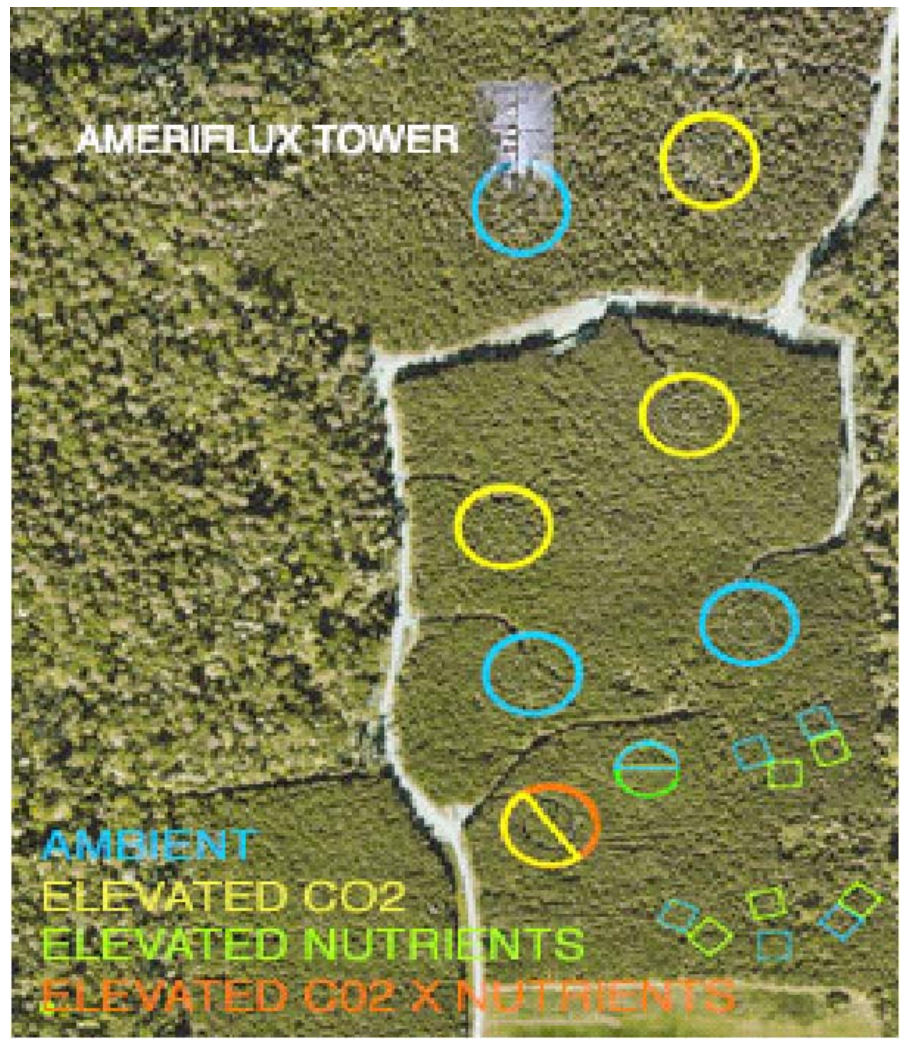

Figure 1. Aerial photo of Duke Forest FACE experiment rings. 

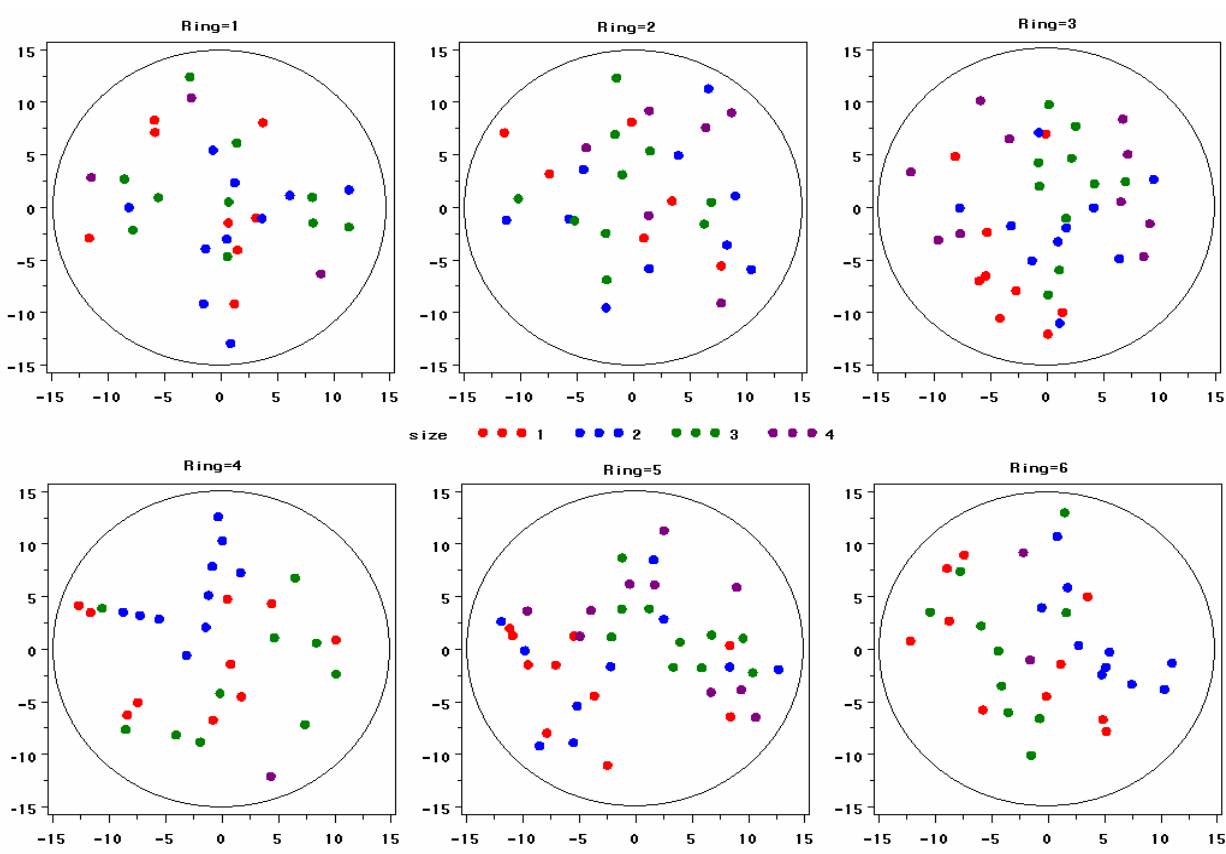

Figure 2. Location of trees used in the study.

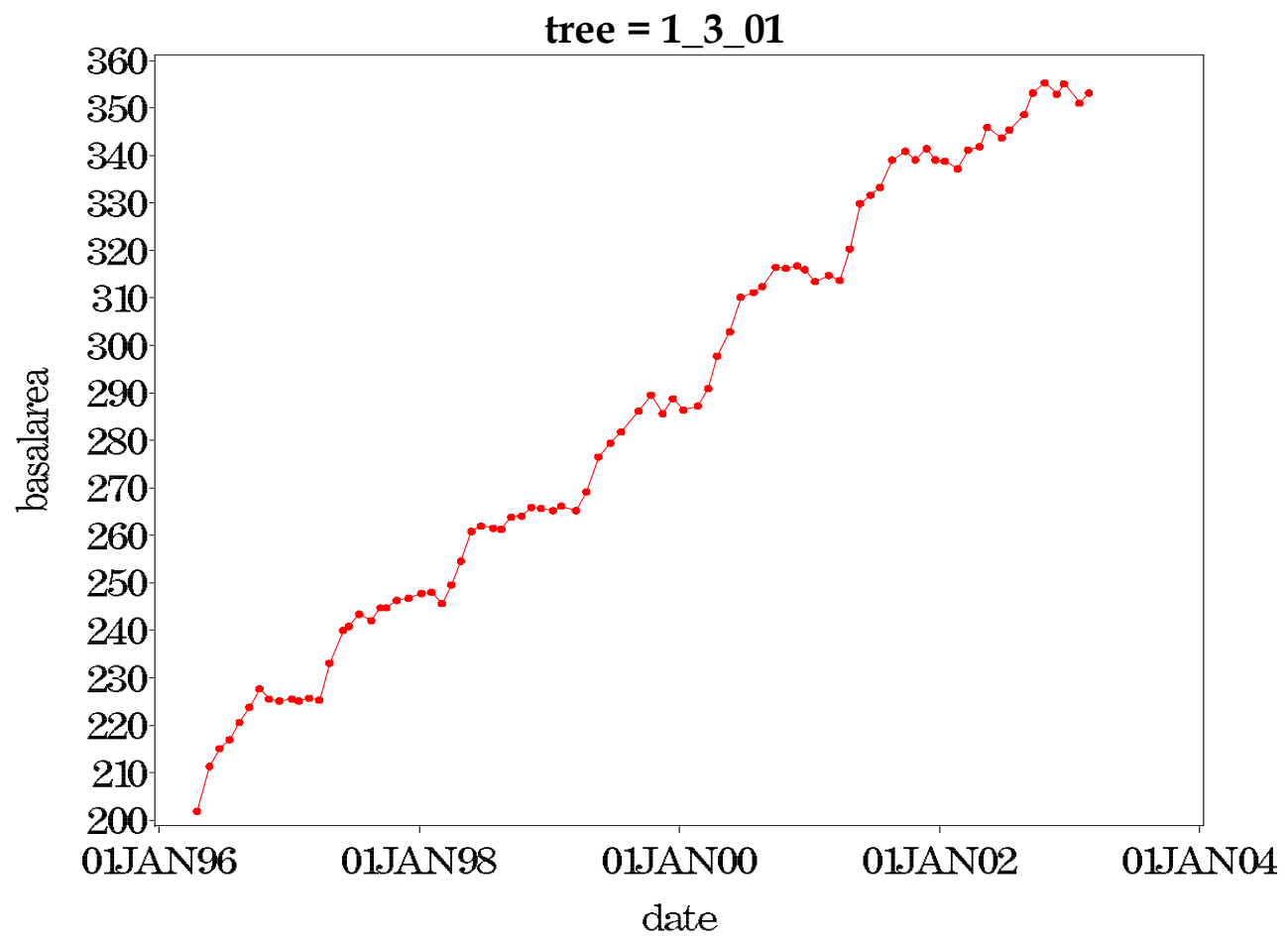

Figure 3. Basal area of tree 1-3-01 from 1996 through 2002. 


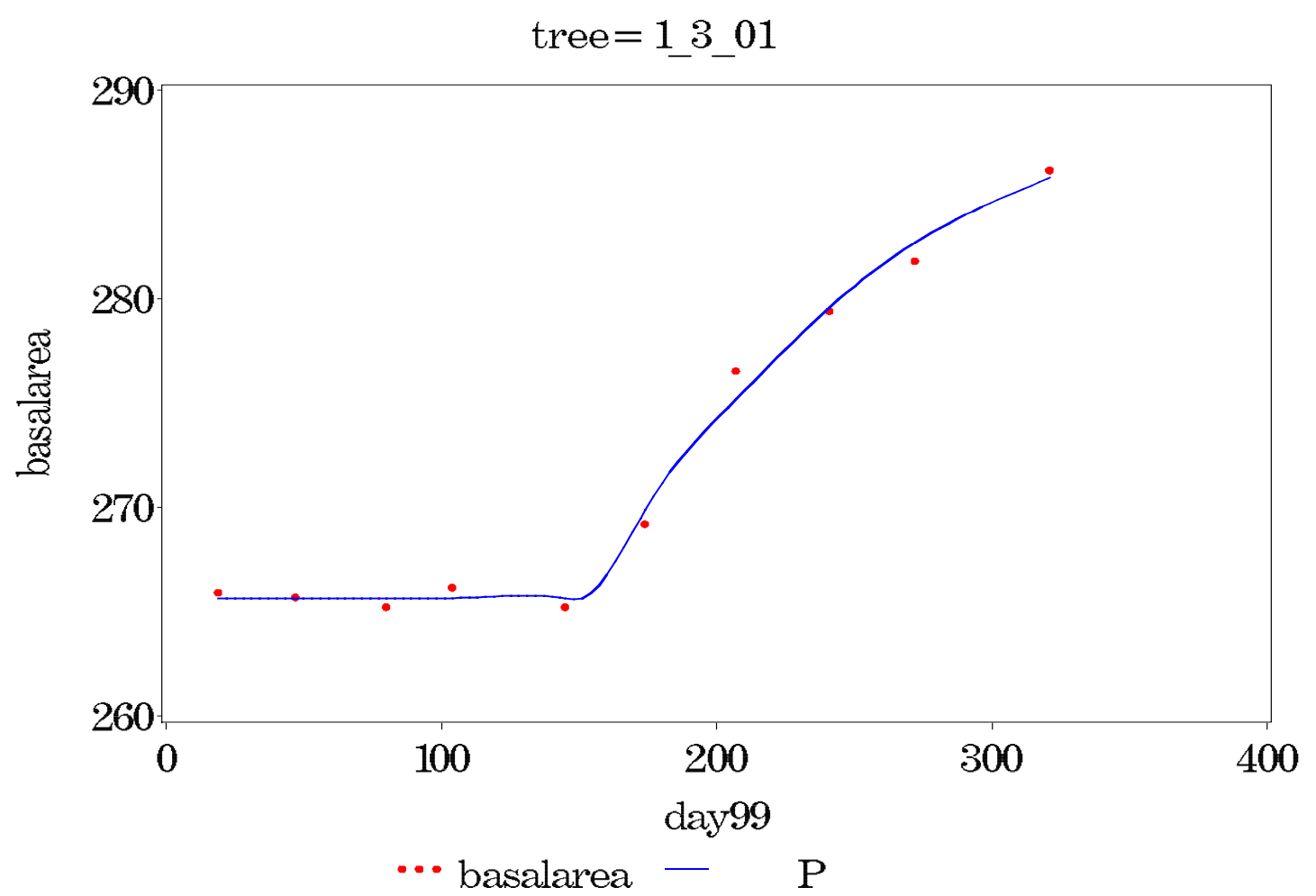

Figure 4. Original data and predicted values from model of onset of growth in 1999.

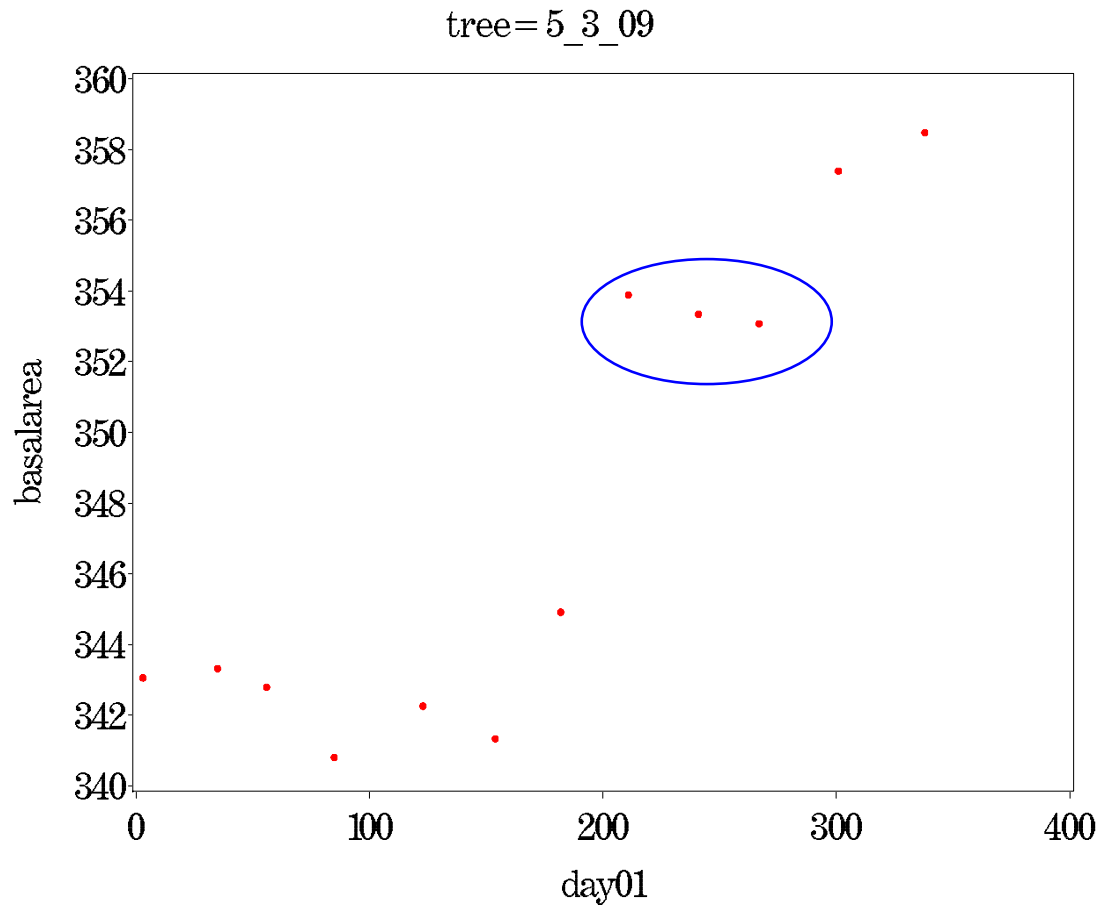

Figure 5. One of the trees with three months of constant data points in 2001. 


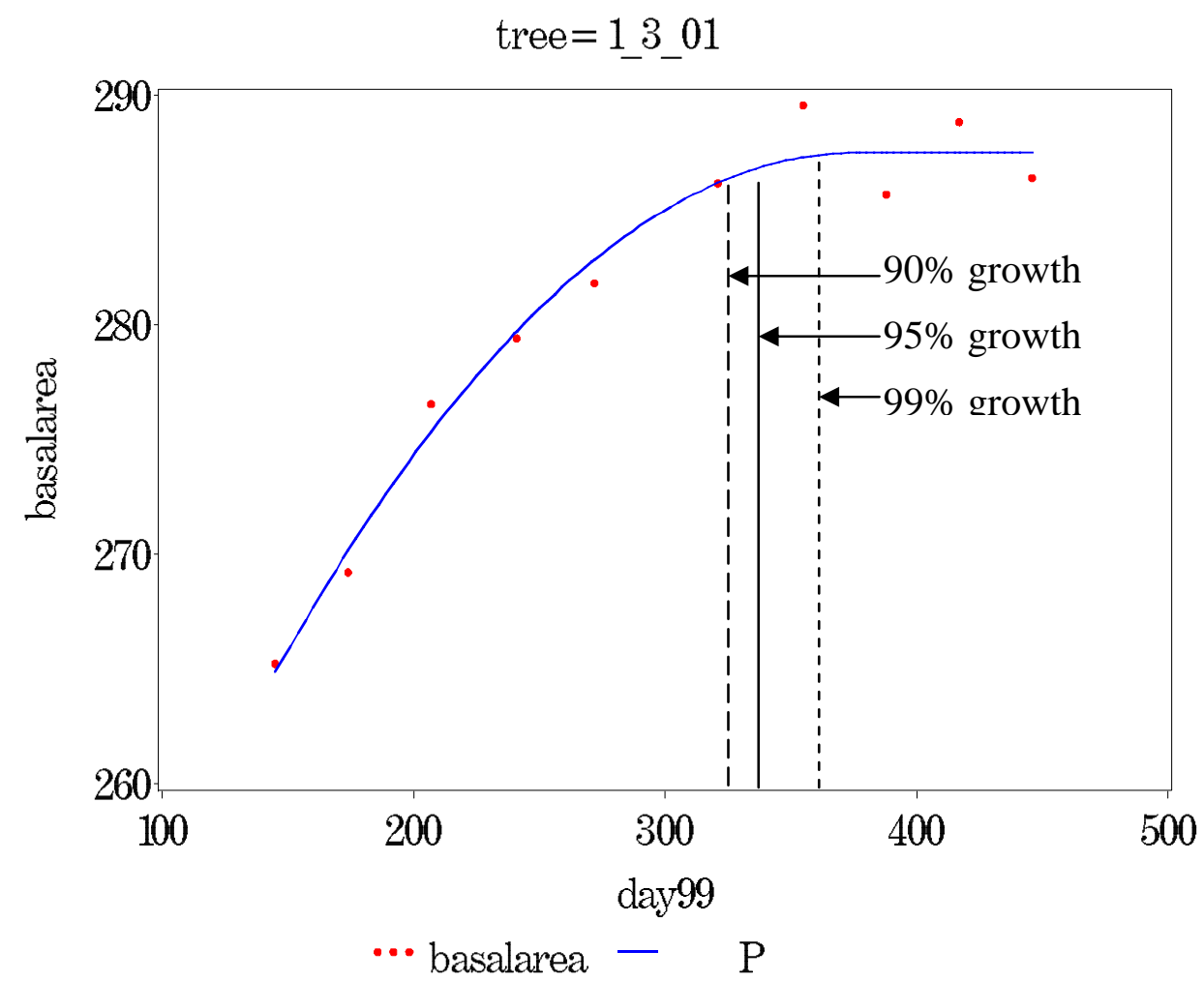

Figure 6. Original data and predicted values from model of cessation of growth in 1999.

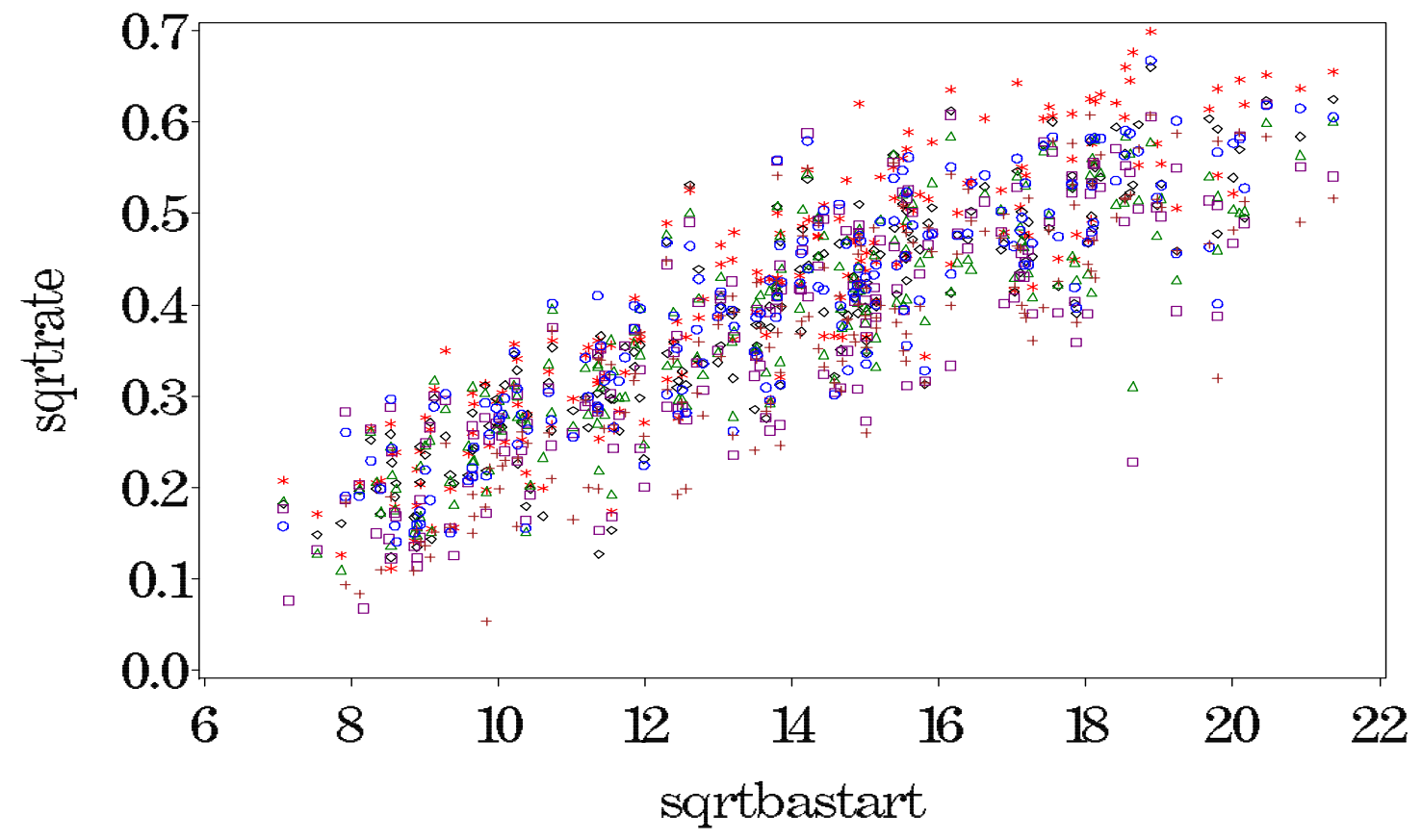

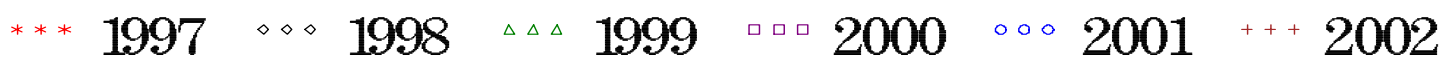

Figure 7. Rates of growth versus the initial basal area (in 1996). 


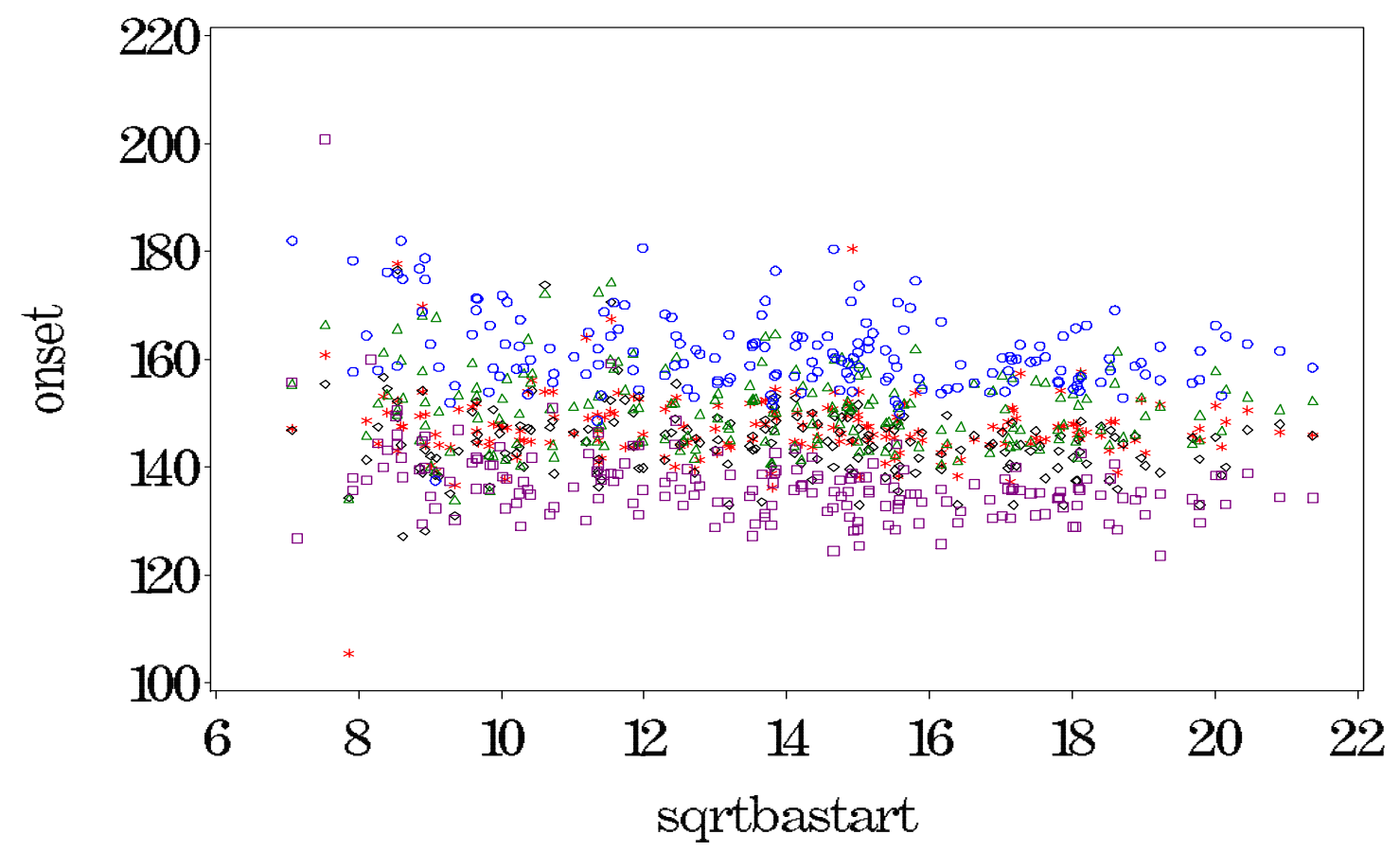

*** 1997 ॰०॰ $1998 \Delta \Delta 1999$ ㅁ 2000 ००० 2001

Figure 8. The onset of growth versus the initial basal area (in 1996).

Estimate

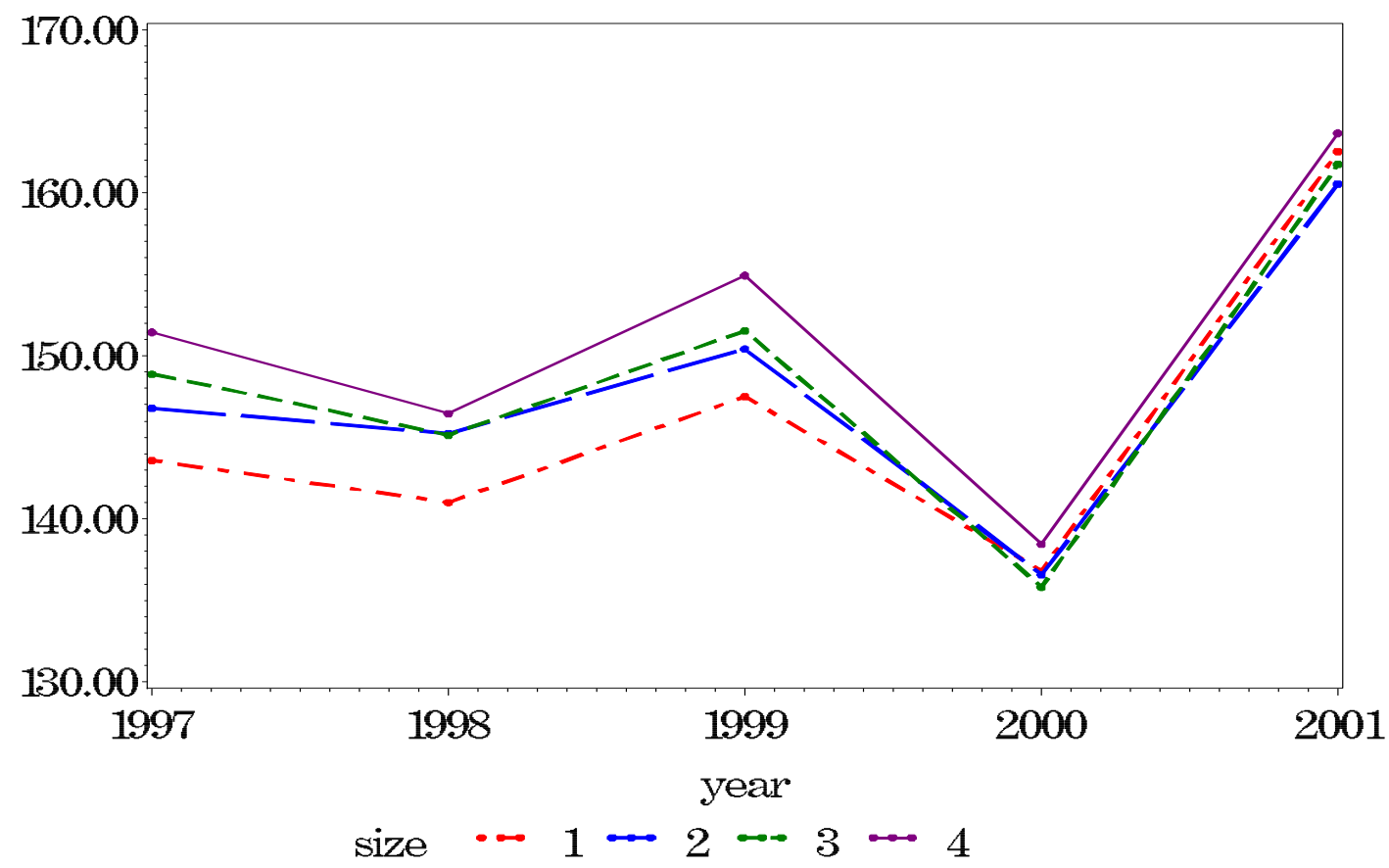

Figure 9. The onset of growth least squares mean versus year for each size class. 


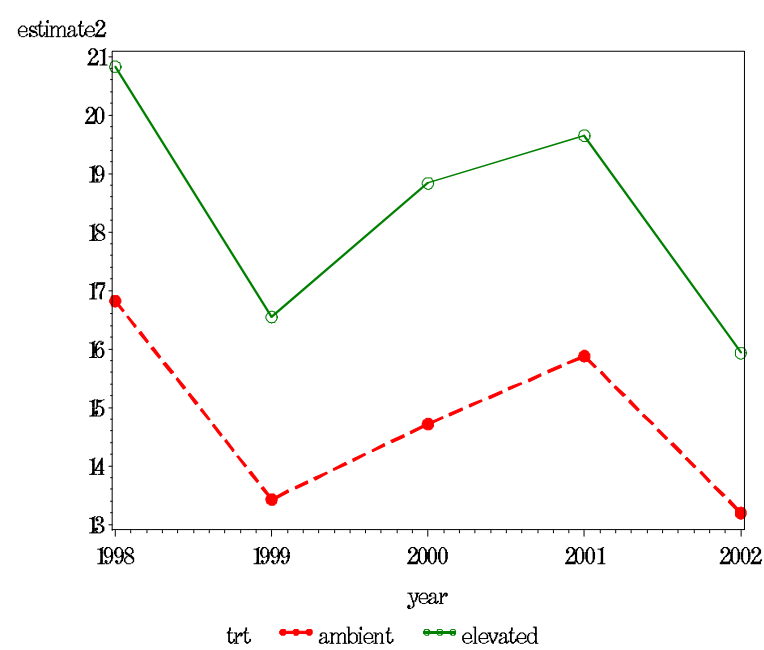

Figure 10. Yearly growth least squares means for each treatment and year.

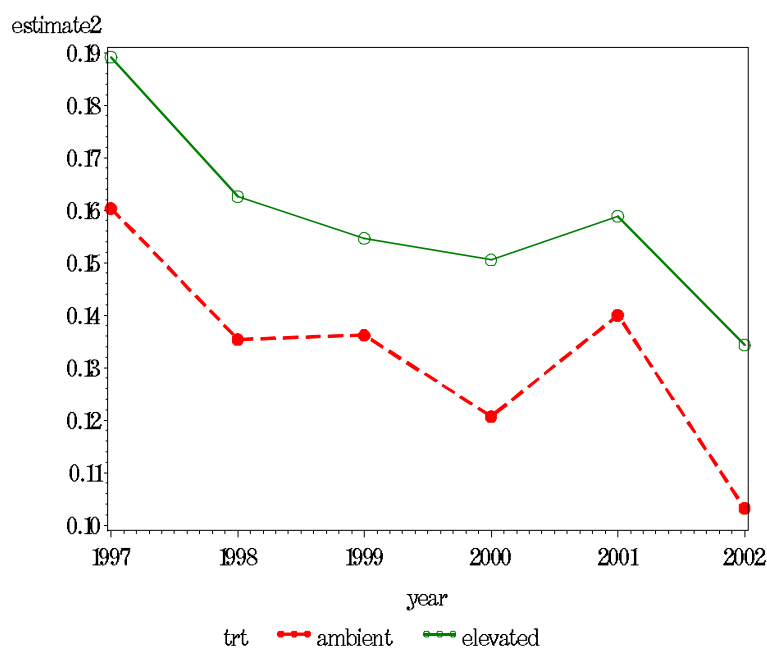

Figure 11 . Yearly rate least squares means for each treatment and year.

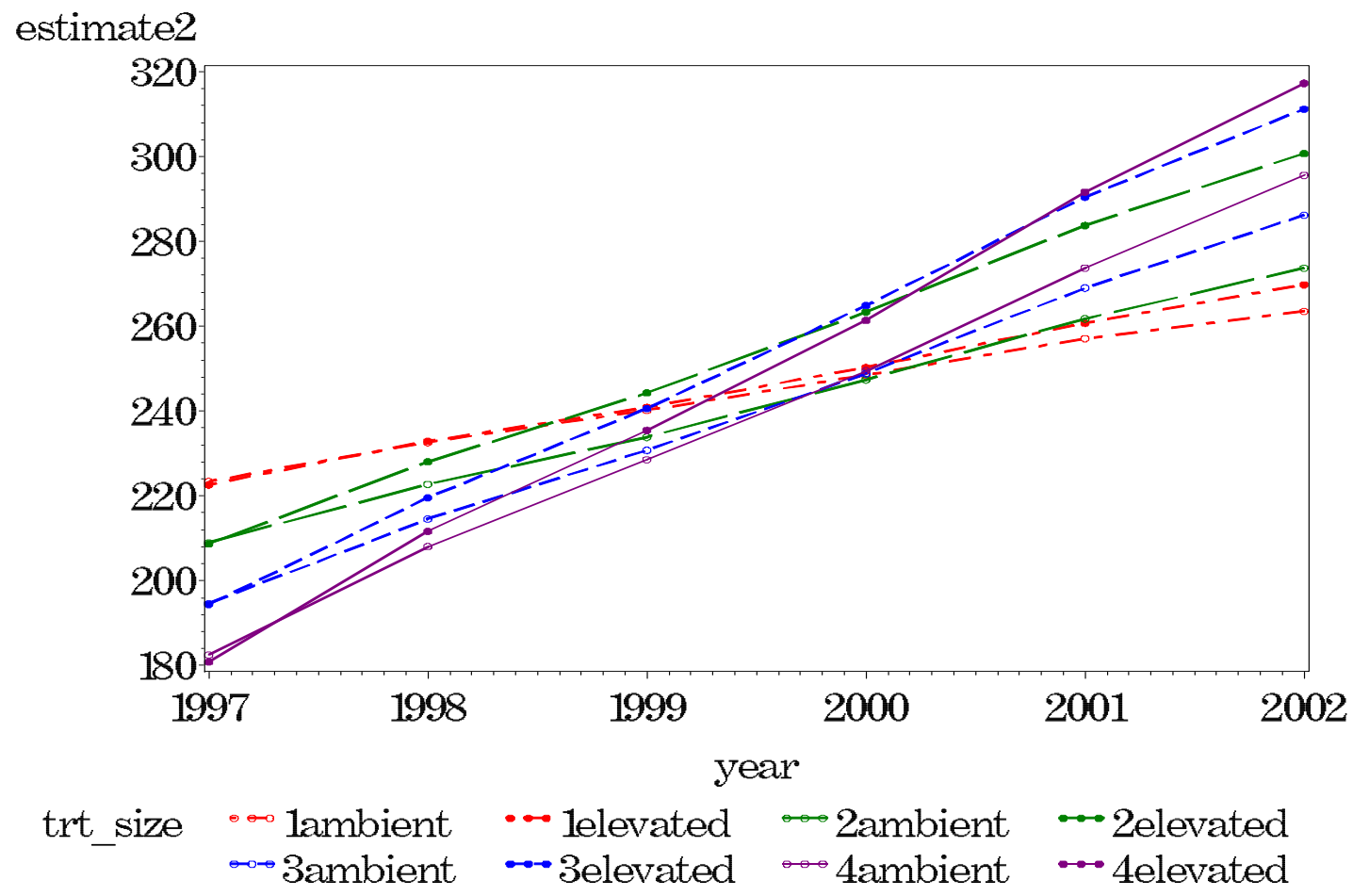

Figure 12. Predicted values from model for actual basal area with year as class. 


\section{TABLES}

Table 1. Fixed effects for the onset of growth variable.

\begin{tabular}{lrrrr} 
Effect & Num & Den & & \\
\hline trt & DF & DF & F Value & Pr $>$ F \\
size & 1 & 2 & 2.12 & 0.2829 \\
year & 3 & 14 & 0.62 & 0.6153 \\
size*year & 4 & 722 & 512.71 & $<.0001$ \\
sqrtbastart & 12 & 722 & 3.64 & $<.0001$ \\
& 1 & 169 & 5.23 & 0.0234
\end{tabular}

Table 2. Fixed effects for the cessation of growth variable.

$\begin{array}{lrrrr}\text { Effect } & \text { Num } & \text { Den } & & \\ \text { trt } & \text { DF } & \text { DF } & \text { F Value } & \text { Pr }>\text { F } \\ \text { size } & 1 & 2 & 2.03 & 0.2906 \\ \text { year } & 3 & 15 & 1.92 & 0.1699 \\ \text { trt* year } & 5 & 912 & 87.05 & <.0001 \\ \text { size* year }^{*} & 5 & 912 & 5.01 & 0.0002 \\ & 15 & 912 & 3.69 & <.0001\end{array}$

Table 3. Correlations of growth period variables.

$$
\begin{aligned}
& \text { Pearson Correlation Coefficients } \\
& \text { Prob }>|r| \text { under HO: Rho=O } \\
& \text { Number of Observations } \\
& \text { cessation growthperiod at } 95 \% \\
& \text { onset } \\
& 0.32465 \\
& -0.46458 \\
& <.0001 \\
& 1096 \\
& <.0001 \\
& 1096 \\
& <.0 \odot \odot 1 \\
& 1096
\end{aligned}
$$

Table 4. Fixed effects for the 95\% growth period variable.

$\begin{array}{lrrrr}\text { Effect } & \text { Num } & \text { Den } & & \\ \text { trt } & \text { DF } & \text { DF } & \text { F Value } & \text { Pr }>\text { F } \\ \text { size } & 1 & 1.97 & 0.28 & 0.6503 \\ \text { year } & 3 & 16.5 & 0.54 & 0.6606 \\ \text { trt*year } & 4 & 612 & 111.17 & <.0001 \\ \text { size*year } & 4 & 611 & 5.20 & 0.0004 \\ \text { sqrtbastart } & 12 & 612 & 3.37 & <.0001 \\ & 1 & 248 & 5.50 & 0.0198\end{array}$


Table 5. Fixed effects for the yearly growth gain variable.

$\begin{array}{lrrrr}\text { Effect } & \text { Num } & \text { Den } & & \\ \text { trt } & \text { DF } & \text { DF } & \text { F Value } & \text { Pr }>\text { F } \\ \text { size } & 1 & 1.96 & 4.14 & 0.1812 \\ \text { year } & 3 & 18.8 & 0.78 & 0.5219 \\ \text { trt*year }^{*} \text { yize*year } & 4 & 684 & 196.10 & <.0001 \\ \text { sqrtbastart } & 4 & 683 & 3.02 & 0.0173 \\ \text { s. } & 12 & 684 & 7.53 & <.0001 \\ & 1 & 183 & 105.47 & <.0001\end{array}$

Table 6. Fixed effects for the growth gain from 1997-2002.

\begin{tabular}{lrrrr} 
& Num & Den & & \\
Effect & DF & DF & F Value & Pr $>$ F \\
\hline trt & 1 & 2 & 13.85 & 0.0652 \\
size & 3 & 14 & 0.36 & 0.7828 \\
sqrtbastart & 1 & 141 & 74.41 & $<.0001$
\end{tabular}

Table 7. Fixed effects for the squareroot of the rate variable.

\begin{tabular}{lrrrr} 
Effect & Num & Den & & \\
\hline trt & DF & DF & F Value & Pr $>$ F \\
size & 1 & 2 & 3.76 & 0.1920 \\
year & 3 & 17.6 & 2.47 & 0.0953 \\
trt*year & 5 & 881 & 108.79 & $<.0001$ \\
size* year $_{\text {sqrtbastart }}$ & 5 & 880 & 3.75 & 0.0023 \\
sqrtar & 15 & 881 & 6.57 & $<.0001$ \\
& 1 & 181 & 115.53 & $<.0001$
\end{tabular}

Table 8. Difference between elevated and ambient levels means for each year.

\begin{tabular}{rrrr} 
year & $\begin{array}{r}\text { Den } \\
\text { DF }\end{array}$ & F Value & Pr $>$ F \\
\hline 1998 & 2.08 & 4.55 & 0.1618 \\
1999 & 2.08 & 3.46 & 0.1992 \\
2000 & 2.08 & 5.39 & 0.1412 \\
2001 & 2.09 & 4.25 & 0.1698 \\
2002 & 2.11 & 2.71 & 0.2348
\end{tabular}


Table 9. Fixed effects for the squareroot of the yearly basal area variable.

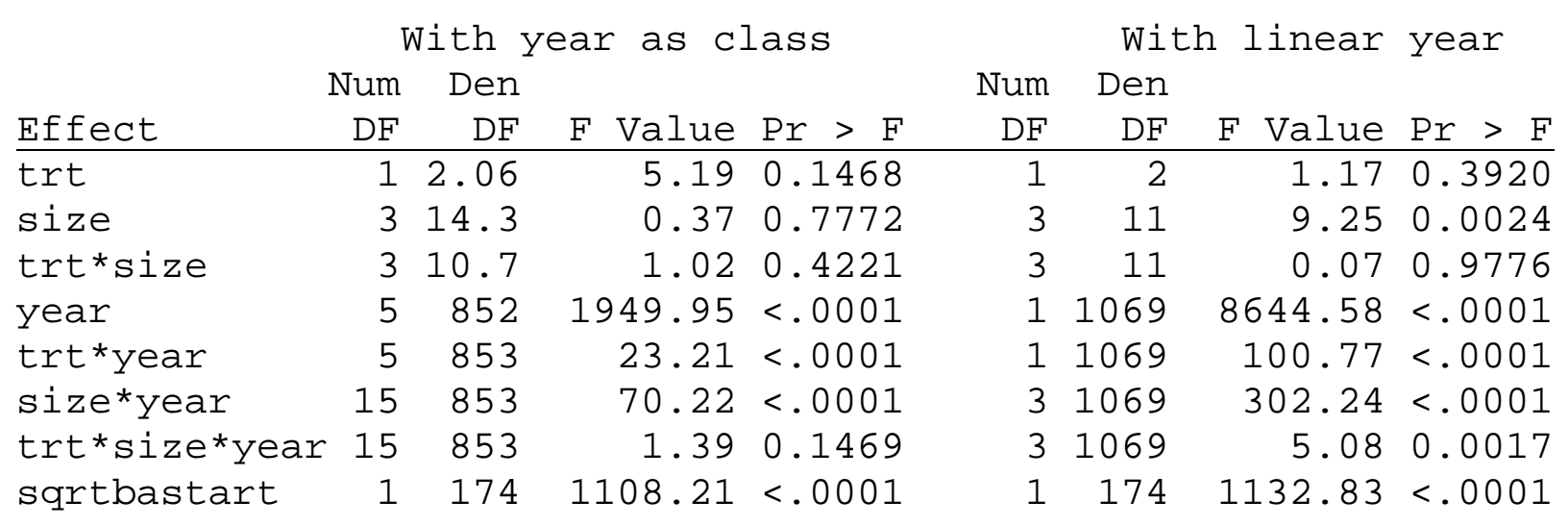

Table 10. Correlations of growth variables.

Prob $>|r|$ under $\mathrm{HO}: \mathrm{Rho}=\mathrm{O} /$ Number of Observations

$\begin{array}{lrr}\text { yearly basal area size } & 0.73393 & 0.80683 \\ & <.0001 & <.0001 \\ & 1108 & 1096 \\ \text { yearly growth gain } & & 0.92388 \\ & & <.0001 \\ & & 1096\end{array}$
growth gain rate

Table 11. Correlations of growth period variables with growth variables.

$$
\begin{gathered}
\text { Pearson Correlation Coefficients } \\
\text { Prob }>|r| \text { under HO: Rho=@ } \\
\text { Number of Observations }
\end{gathered}
$$$$
\text { yearly basal area size yearly growth }
$$

rate

onset

$\begin{array}{rr}-0.07188 & -0.24201 \\ 0.0284 & <.0001 \\ 930 & 930\end{array}$

cessation1

0.12234

0.0002

947

growthperiod at $95 \%$

$$
\begin{array}{r}
0.13603 \\
<.0001 \\
930
\end{array}
$$

0.30005

$<.0001$

937

0.33092

$<.0001$

930
$-0.09505$

0.0034

945

0.12923

$<.0001$

930

0.14379

$<.0001$
930 